\title{
Bidentate and Tridentate Heterocyclic Azo Compounds Having Long Alkyl Chains as Coating Reagents for Ion Chromatography of Manganese, Zinc, and Cadmium Ions
}

\author{
Takashi Yasui, ${ }^{\dagger}$ Nozomu Komatsu, Kazuki Egami, Hiromichi Yamada, and Akio Yuchi \\ Graduate School of Engineering, Nagoya Institute of Technology, Gokiso, Showa, Nagoya 466-8555, Japan
}

\begin{abstract}
Bidentate and tridentate heterocyclic azo compounds with and without a long alkyl chain were prepared and examined for cation exchange chromatography of manganese, zinc, and cadmium; these ions could not be separated by reversed phase HPLC following precolumn derivatization with heterocyclic azo compounds owing to the dissociation of the complexes. The newly prepared azo compounds having a long alkyl chain favorably orientate in the reversed-phase stationary phase such that the coordinating parts of the ligand may make contact with metal ions in the mobile phase. Bidentate ligands showed sharp peaks but almost no resolution of manganese and cadmium. A tridentate ligand strongly retained all the three metal ions, which could be separated within $10 \mathrm{~min}$ by a competing ligand and by optimizing the $\mathrm{pH}$.
\end{abstract}

(Received February 23, 2007; Accepted May 22, 2007; Published August 10, 2007)

\section{Introduction}

One of the effective methods for simultaneous determination of metal ions is reversed-phase HPLC separation coupled with spectrophotometry. The intrinsically high performance of reversed-phase stationary phases developed for the separation of organic compounds is applicable to inorganic cations after precolumn derivatization. Various derivatizing reagents, such as dithiocarbamates, ${ }^{1-3} \quad 8$-quinolinol, ${ }^{4,5}$ porphyrins, ${ }^{6-8}$ and heterocyclic azo dyes, ${ }^{9-11}$ have been developed and examined considering the sample compositions. We have also synthesized a series of heterocyclic azo compounds and extensively studied the retention behavior of the reagent and their metal complexes. ${ }^{12-18}$ With this type of reagent, the complexes of iron, cobalt, nickel, and copper are sufficiently stable to enable separation in the column. In contrast, the complexes of manganese, zinc, and cadmium are dissociated in the column after separation from excess reagent and usually can not be detected. ${ }^{19}$ This lability, however, suggests the possibility of cation exchange chromatography of these weakly interacting metal ions.

Chromatographic separation of metal ions using complexation has been developed in order to achieve different selectivity patterns from that of conventional ion chromatography. Stationary phases obtained by physical adsorption of chelating reagents on the surface of high-performance reversed-phase substrates are especially versatile..$^{20-25}$ Continuous supply from the mobile phase is necessary for reagents of less lipophilicity (dynamic coating), ${ }^{22-25}$ while durable coating is possible for highly lipophilic reagents (precoating). ${ }^{20-23}$ In this study, we have synthesized a series of azo reagents with and without a long alkyl chain which enhanced the distribution of the reagent into the stationary phase and have evaluated their performances as a precoating reagent on an octadecylsilyl column for the separation of manganese, zinc, and cadmium ions.

$\dagger$ To whom correspondence should be addressed.

E-mail: yasui.takashi@nitech.ac.jp

\section{Experimental}

\section{Apparatus}

The HPLC system consisted of two Model PU-980 intelligent pumps, a Model 9725i sample injector with a 10- $\mu$ l sample loop, a Model 965-CO column oven, and a Model MD-915 multiwavelength UV-Vis detector (wavelength range 200 - 800 nm) equipped with a Model DP-L915 data processing system (Jasco, Tokyo, Japan). A Model CD-5 conductometric detector (Showa Denko, Tokyo, Japan) was also used to monitor the elution of metal ions. Two C8 bonded silica gel columns (Model Unisil Q C8 and Model Inertsil C8, GL Science, Tokyo, Japan) and one C18 bonded silica gel column (Model L-column ODS, Chemical Evaluation Research Institute, Tokyo, Japan) of the same dimension $(4.6 \mathrm{~mm}$ i.d. $\times 250 \mathrm{~mm}$, particle diameter 5 $\mu \mathrm{m})$ were employed as a stationary phase. The absorption spectra were recorded with a Model UV-2200A spectrophotometer (Shimadzu, Tokyo, Japan). ${ }^{1} \mathrm{H}-\mathrm{NMR}$ spectra were measured with a Model Gemini 300 spectrometer (300 MHz, Varian, CA, USA).

\section{Reagents}

The structures of compounds used in the present study are shown in Table 1. Among the parent compounds, 2-(2pyridylazo)-1-naphthol ( $\alpha$-PAN $)^{26}$ and 4-(2-pyridylazo)-1-naphthol $(p \text {-PAN })^{27}$ were prepared by condensation of 2-hydrazinopyridine with 1,2-naphthoquinone and 1,4-naphthoquinone, respectively. 1-(2-Pyridylazo)-2-naphthol $(\beta \text {-PAN })^{28}$ was synthesized by coupling a 2-pyridinediazonium salt with 2-naphthol, while 4-(2-thiazolylazo)-1-naphthol $(p \text {-TAN })^{29}$ was synthesized by coupling a 2-thiazolediazonium salt with 1-naphthol. Each crude compound was purified by extraction of their chloroform solutions with acid and alkali and by recrystallization from ethanol-water. 2-(2-Pyridylazo)-4-methylphenol (PAC) ${ }^{30}$ was used as obtained.

One of the long alkyl derivatives, 2-(2-pyridylazo)-4-(octyloxy)phenol (PAOOP), was synthesized by coupling 2pyridinediazonium salt with 4-(octyloxy)phenol. The isomers were separated by extraction of the hexane solution with 0.01 mol dm${ }^{-3}$ sodium hydroxide in acetone-water $(50: 50, \mathrm{v} / \mathrm{v})$. Other 
Table 1 Dissociation constants of heterocyclic azo compounds (ethanol-water, 50:50 (v/v); $I=0.1 \mathrm{~mol} \mathrm{dm}^{-3} \mathrm{KCl}$ )

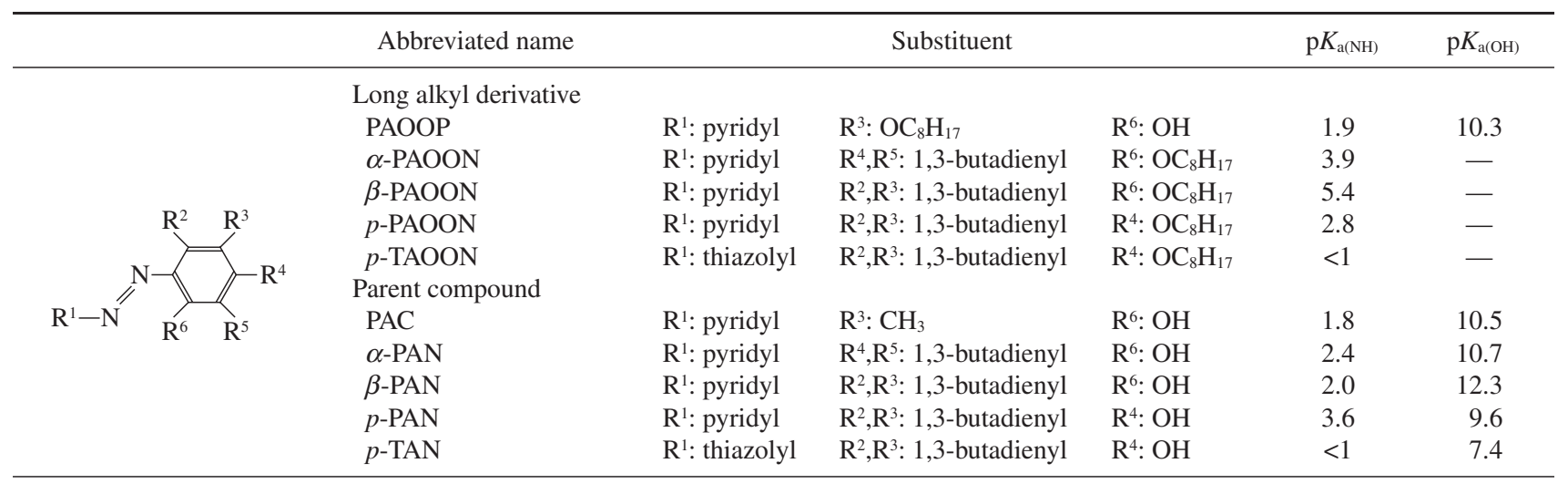

long alkyl derivatives were prepared by Williamson ether synthesis with 1-bromooctane and the parent pyridylazo- and thiazolylazonaphthols. ${ }^{31,32}$ A 30\% sodium carbonate solution containing cetyltrimethylammonium bromide was used for 2-(2-pyridylazo)1-(octyloxy)naphthalene $(\alpha$-PAOON) and 1-(2-pyridylazo)-2(octyloxy)naphthalene ( $\beta$-PAOON), while sodium hydride in $N, N$-dimethylformamide was used for 4-(2-pyridylazo)-1(octyloxy)naphthalene ( $p$-PAOON) and 4-(2-thiazolylazo)-1(octyloxy)naphthalene ( $p$-TAOON). The crude materials were purified by chromatography on silica-gel column, by extraction with acid and alkali, or by precipitation from ethyl acetate solution by the addition of $n$-hexane. The purities of the compounds were confirmed by ${ }^{1} \mathrm{H}$ NMR and reversed-phase HPLC.

Each compound was dissolved in ethanol or ethanol-water to give a $1 \times 10^{-3} \mathrm{~mol} \mathrm{dm}^{-3}$ solution for column-coating and $2.5 \times$ $10^{-5} \mathrm{~mol} \mathrm{dm}{ }^{-3}$ solution for the batch experiments. Standard stock solutions $\left(1.0 \times 10^{-2} \mathrm{~mol} \mathrm{dm}^{-3}, \mathrm{pH} 2\right)$ of zinc, manganese, and cadmium were prepared by dissolving the analyticalreagent grade nitrates.

\section{Chromatographic procedure}

The reversed-phase columns were coated with each compound by passing the $1 \times 10^{-3} \mathrm{~mol} \mathrm{dm}^{-3}$ ethanol-water solutions for $2 \mathrm{~h}$, followed by washing with water for $1 \mathrm{~h}$ at a flow rate of $0.3 \mathrm{~cm}^{3}$ $\mathrm{min}^{-1}$ and at a column temperature of $40^{\circ} \mathrm{C}$. A $10-\mu \mathrm{l}$ aliquot of $1 \times 10^{-3} \mathrm{~mol} \mathrm{dm}^{-3}$ metal ion solution was placed on the column via an injection valve and eluted with a mobile phase at a flow rate of $0.7 \mathrm{~cm}^{3} \mathrm{~min}^{-1}$ and at a column temperature of $40^{\circ} \mathrm{C}$. An aqueous solution $\left(1 \times 10^{-4} \mathrm{~mol} \mathrm{dm}^{-3}\right.$, approximately $\left.\mathrm{pH} 10\right)$ of 2-(2-thiazolylazo)resorcinol (TAR) or 2-(2-pyridylazo)resorcinol (PAR) as a postcolumn derivatizing reagent was merged with the eluent, and the absorbance was monitored at 200-800 nm. The void volumes used to calculate $k^{\prime}$ values were determined by injecting pure water into each mobile phase.

\section{Results and Discussion}

Reactions with metal ions in solution and spectral changes

The acid dissociation constants of five newly synthesized compounds as well as their parent compounds were spectrophotometrically determined at an ionic strength of 0.1 mol dm ${ }^{-3} \mathrm{KCl}$ in ethanol-water (50:50, v/v), which allowed the solubilization of these reagents in the presence of metal ions over a wide $\mathrm{pH}$ range of $3-11$ (Table 1). The introduction of an octyl group enhanced the basicities of nitrogen atoms of $\alpha$-PAN and $\beta$-PAN but not for PAC, $p$-PAN, and $p$-TAN. The basicity decreased in the order of: $\beta$-PAOON $>\alpha$-PAOON $>$

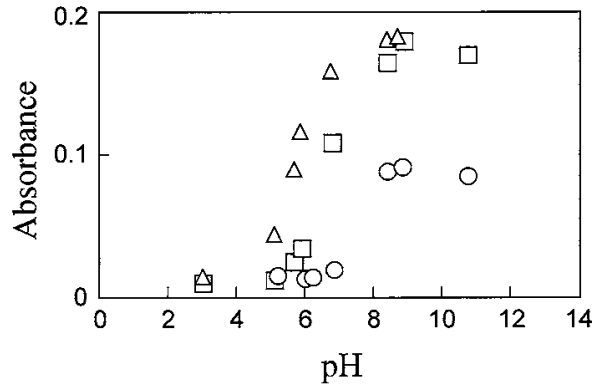

Fig. 1 Effect of $\mathrm{pH}$ on absorbance of binary systems consisting of PAOOP and metal ions. Metal, $1 \times 10^{-5}$; PAOOP, $1 \times 10^{-5}$; buffer, 1 $\times 10^{-2} \mathrm{~mol} \mathrm{dm}^{-3}$. Ethanol-water $(50: 50, \mathrm{v} / \mathrm{v}) ; 25^{\circ} \mathrm{C}$. Metal, wavelength: $\triangle, \mathrm{Zn}, 586$; $\square, \mathrm{Cd}, 581 ; \mathrm{O}, \mathrm{Mn}, 575 \mathrm{~nm}$.

$p$-PAOON $>$ PAOOP $>p$-TAOON. The resulting compounds showed the absorption maximum at a longer wavelength than the parent compounds; e.g., $545 \mathrm{~nm}$ for $\alpha$-PAOON compared with $485 \mathrm{~nm}$ for $\alpha$-PAN and $538 \mathrm{~nm}$ for $\beta$-PAOON compared with $470 \mathrm{~nm}$ for $\beta$-PAN.

The reactivities of these compounds to three metal ions $\left(\mathrm{Mn}^{2+}\right.$, $\mathrm{Zn}^{2+}$, and $\mathrm{Cd}^{2+}$ ) were estimated from the change in absorption spectrum. Practically no changes were obtained for bidentate ligands of $\alpha$-PAOON, $\beta$-PAOON, $p$-PAOON, and $p$-TAOON, while appreciable changes were observed for tridentate PAOOP. The absorption spectrum of binary systems consisting of PAOOP and $\mathrm{Mn}^{2+}, \mathrm{Zn}^{2+}$, and $\mathrm{Cd}^{2+}$ was measured at varying $\mathrm{pH}$ values. The absorbances at wavelengths characteristic of each metal ion are shown as a function of $\mathrm{pH}$ in Fig. 1. The changes in absorbance caused by complexation were found at $\mathrm{pH}>5$ for $\mathrm{Zn}^{2+}$, at $\mathrm{pH}>6$ for $\mathrm{Cd}^{2+}$, and at $\mathrm{pH}>7$ for $\mathrm{Mn}^{2+}$. The $\mathrm{pH}$ profiles indicated that the reactivity of PAOOP to metal ions was in the order of: $\mathrm{Zn}^{2+}>\mathrm{Cd}^{2+}>\mathrm{Mn}^{2+}$.

The reactivity of $p$-PAOON, as a representative of bidentate ligands, to metal ions was examined by ${ }^{1} \mathrm{H}$ NMR in acetone$d_{6}-\mathrm{D}_{2} \mathrm{O}(70: 30, \mathrm{v} / \mathrm{v})$. All the aromatic protons were unambiguously assigned as shown in Fig. 2(A). Although the addition of $\mathrm{Zn}^{2+}$ caused no chemical shift of these protons due to the lability of the complex, a pronounced broadening of protons adjacent to the azo group was observed (Fig. 2(B)). Cadmium ion also caused the broadening to a lesser extent, but manganese did not. The broadening indicated that the reactivities of bidentate ligands were also in the order of: $\mathrm{Zn}^{2+}>\mathrm{Cd}^{2+}>\mathrm{Mn}^{2+}$.

Preliminary studies on reagents and columns

The L-column ODS was coated with six reagents by adjusting 
(A)
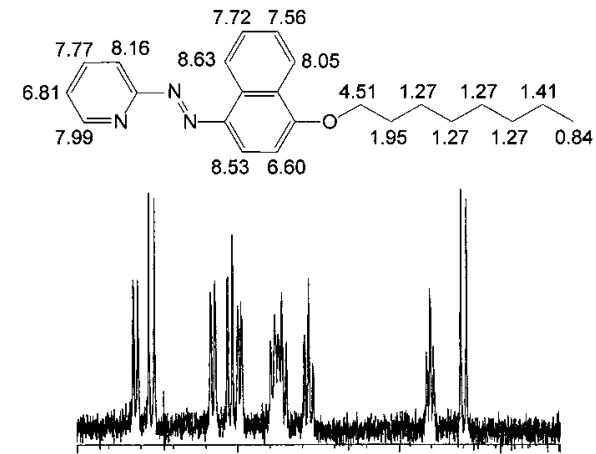

(B)

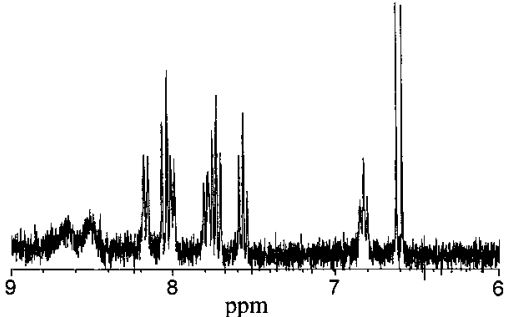

Fig. $2 \quad{ }^{1} \mathrm{H}-\mathrm{NMR}$ spectra of $p$-PAOON (A) and Zn-p-PAOON complex (B). Solvent: acetone- $d_{6}-\mathrm{D}_{2} \mathrm{O}(70: 30, \mathrm{v} / \mathrm{v})$ containing $0.03 \%$ TMS.

the ethanol/water ratio of the solvent to have comparable coated amounts: $2.10 \mu \mathrm{mol}$ for PAOOP, $6.25 \mu \mathrm{mol}$ for $\alpha$-PAOON $6.45 \mu \mathrm{mol}$ for $\beta$-PAOON, $2.23 \mu \mathrm{mol}$ for $p$-PAOON, $7.26 \mu \mathrm{mol}$ for $\alpha$-PAN, and $7.47 \mu \mathrm{mol}$ for $\beta$-PAN. The retention of $\mathrm{Zn}^{2+}$ and $\mathrm{Mn}^{2+}$ was preliminarily studied on these columns. Among three tridentate ligands, PAOOP showed much larger retention of $\mathrm{Zn}^{2+}$ in spite of the lesser coating amount compared with $\alpha$-PAN and $\beta$-PAN (Fig. 3(A)). This suggests the favorable orientation of PAOOP in the stationary phase on the complexation with metal ions in a mobile phase; the coordinating site of PAOOP may be located on the outer side of alkyl chains of the stationary phase. In contrast, $\alpha$-PAN and $\beta$-PAN were expected to be distributed deep in the stationary phase.

The three bidentate compounds of $\alpha$-PAOON, $\beta$-PAOON, and $p$-PAOON showed less retention of metal ions than tridentate ligands (Fig. 3(B)). Among these, $p$-PAOON had the greatest retention in spite of having the lowest basicity. In $p$ PAOON, potentially coordinating atoms are located on the opposite side of a long alkyl chain distributed into the stationary phase and may favorably accommodate metal ions in the mobile phase. In summary, the phenolic $\mathrm{OH}$ group was indispensable in obtaining appreciable retention, and PAOOP was adopted for further examination.

Three columns were examined for the separation of metal ions using PAOOP. Compared with two C8 columns, L-column ODS afforded a much larger retention of $\mathrm{Zn}^{2+}$ because of the higher loading ability of PAOOP, but occasionally showed peak-splitting for $\mathrm{Zn}^{2+}$. The splitting was also observed with Inertsil C8. In contrast, Unisil Q C8 gave a reproducible chromatogram. Moreover, $\mathrm{Mn}^{2+}$ was appreciably retained only on Unisil Q C8 because of the interaction with the residual silanol group. ${ }^{33}$ Thus, Unisil Q C8 was used for further studies.

Optimization of chromatographic parameters and chromatograms The effect of $\mathrm{pH}$ on the retention of metal ions on Unisil Q C8 with and without PAOOP is shown in Fig. 4. The effect of $\mathrm{pH}$ on the acid-base equilibrium of oxalate $\left(\mathrm{p} K_{\mathrm{a}}=1.19,4.21\right)$ added in the mobile phase was negligible at $\mathrm{pH}>5$. In the presence of $\mathrm{PAOOP}$, the retention steeply increased with an increase in $\mathrm{pH}$.
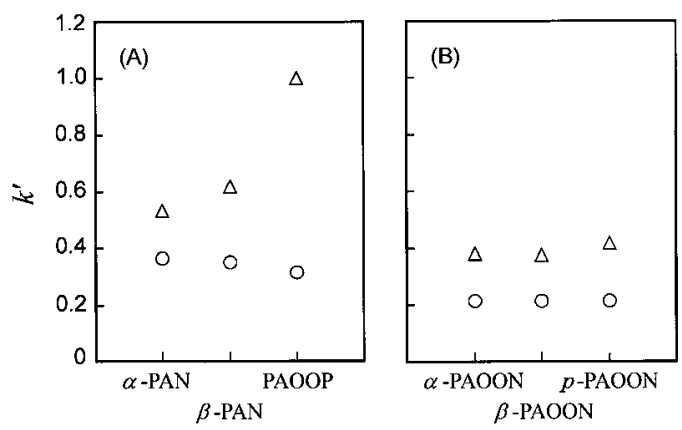

Fig. 3 Comparison of coating ligands. Column, L-column ODS; eluent, $2 \times 10^{-3} \mathrm{~mol} \mathrm{dm}^{-3}$ oxalate, (A) $\mathrm{pH} 6$, (B) $\mathrm{pH} 6.5$; flow-rate, $0.7 \mathrm{~cm}^{3} \mathrm{~min}^{-1}$; column temperature, $40^{\circ} \mathrm{C}$. Metal: $\triangle, \mathrm{Zn} ; \mathrm{O}, \mathrm{Mn}$.

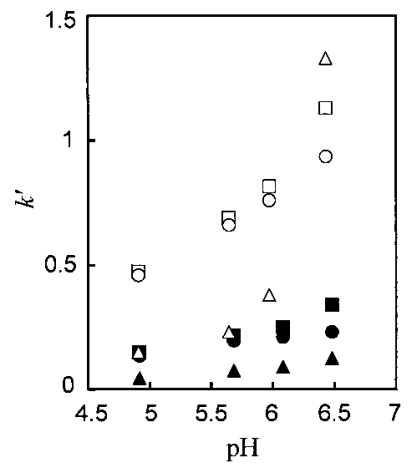

Fig. 4 Effect of $\mathrm{pH}$ on retention of metal ions with and without coating of PAOOP. Column, Unisil Q C8; eluent, $1 \times 10^{-3} \mathrm{~mol} \mathrm{dm}^{-3}$ oxalate; flow-rate, $0.7 \mathrm{~cm}^{3} \mathrm{~min}^{-1}$; column temperature, $40^{\circ} \mathrm{C}$. Metal: $\triangle, \mathrm{Zn}$; $\square, \mathrm{Cd} ; \mathrm{O}, \mathrm{Mn}$ (coated with PAOOP); $\mathbf{\Delta}, \mathrm{Zn}$; $\mathbf{\bullet}, \mathrm{Cd}$; $\bullet, \mathrm{Mn}$ (uncoated).

The retention of $\mathrm{Zn}^{2+}$ enhanced sufficiently to result in a change in elution order at $\mathrm{pH}>6$; this agrees with the complexation behavior in solutions shown in Fig. 1. In the absence of PAOOP, on the other hand, the retention was only slightly increased due to the interaction with the residual silanol. The effect of PAOOP was larger for $\mathrm{Mn}^{2+}$ and $\mathrm{Cd}^{2+}$ compared with that for $\mathrm{Zn}^{2+}$ at $\mathrm{pH}$ 5. This suggests a different type of interaction between metal ions and PAOOP; an interaction through pyridyl and azo nitrogen atoms without the involvement of phenolate oxygen.

The performance of five anions as an eluent was compared at a total concentration of $6.0 \times 10^{-3} \mathrm{~mol} \mathrm{dm}^{-3}$ and at $\mathrm{pH} 6.5$ (Fig. 5). All the metal ions were not retained with citrate (the stability constant of zinc complex, $\left.K_{\mathrm{ZnA}}=10^{5.2}\right),{ }^{34}$ while zinc was not eluted either with thiocyanate $\left(K_{\mathrm{ZnA}}=10^{0.25}\right),{ }^{35}$ chloride $\left(K_{\mathrm{ZnA}}=10^{0.78}\right),{ }^{35}$ or tartrate $\left(K_{\mathrm{ZnA}}=10^{2.69}\right) \cdot{ }^{34}$ Relatively sharp peaks with a reasonable retention time were obtained with oxalate $\left(K_{\mathrm{ZnA}}=10^{4.9}\right)^{34}$ at 1 to $2 \times 10^{-3} \mathrm{~mol} \mathrm{dm}^{-3}$.

The effect of ethylenediammonium cation as a competing reagent to residual silanol groups was examined; sharp peaks for $\mathrm{Mn}^{2+}$ and $\mathrm{Cd}^{2+}$ were obtained and the retention was reduced, while the retention of $\mathrm{Zn}^{2+}$ was not affected. The concentration was optimized to $1 \times 10^{-3} \mathrm{~mol} \mathrm{dm}^{-3}$.

Typical chromatograms by conductometry and spectrophotometry are shown in Figs. 6(A) and 6(B), respectively. Baseline separation of three metal ions within 10 min was achieved. The peak height for $\mathrm{Mn}^{2+}$ with spectrophotometry was low due to the interference of oxalate to the postcolumn color-forming reaction. 


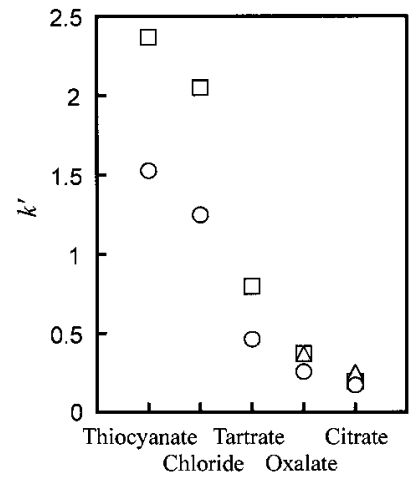

Fig. 5 Effect of additives on retention of metal ions. Column, Unisil Q C8 coated with PAOOP; eluent, $6 \times 10^{-3} \mathrm{~mol} \mathrm{dm}^{-3}$ additive solution, $\mathrm{pH} 6.5$; flow-rate, $0.7 \mathrm{~cm}^{3} \mathrm{~min}^{-1}$; column temperature, $40^{\circ} \mathrm{C}$. Metal: $\triangle, \mathrm{Zn} ; \square, \mathrm{Cd} ; \mathrm{O}, \mathrm{Mn}$.
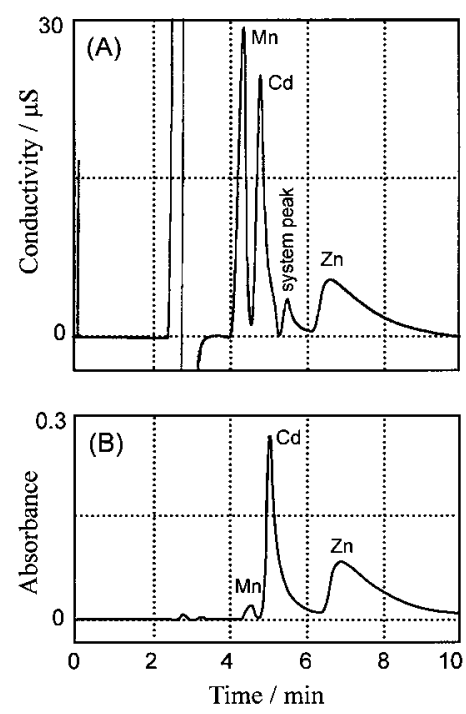

Fig. 6 Typical chromatograms of metal ions with coating of PAOOP. (A) Conductometric detection; (B) spectrophotometric detection. Column, Unisil Q C8; eluent, $1 \times 10^{-3} \mathrm{~mol} \mathrm{dm}^{-3}$ oxalate containing $1 \times 10^{-3} \mathrm{~mol} \mathrm{dm}^{-3}$ ethylenediammonium ion, $\mathrm{pH} 6.5$; flowrate, $0.7 \mathrm{~cm}^{3} \mathrm{~min}^{-1}$; column temperature, $40^{\circ} \mathrm{C}$.

Heterocyclic azo compounds were coated on the reversedphase HPLC columns, which were examined for ion-exchange chromatographic separation of metal ions. During the procedure, none the compounds with or without a long alkyl chain leaked from the column with aqueous eluent and exhibited retention behavior characteristic of metal ions. A long alkyl chain not only enhanced the distribution of the azo compounds but oriented the donor atoms suitably for the interaction with metal ions in the mobile phase.

In this study, manganese with small affinities to the heterocylic azo compounds was retained by the interaction of the residual silanol group. Another possibility for the retention of manganese is the introduction of anion-exchange sites such as sulfonates on the present heterocyclic azo compounds.

\section{References}

1. M. Petsch, J. Seipelt, and B. X. Mayer-Helm, Anal. Chim.
Acta, 2004, 516, 119.

2. J. Wang and K. Chiu, Anal. Sci., 2004, $20,841$.

3. L. Dong, X. Yan, Y. Li, Y. Jiang, S. Wang, and D. Jiang, J. Chromatogr., A, 2004, 1036, 119.

4. M. T. Kelly and A. Blaise, J. Chromatogr., A, 2006, 1134, 74.

5. H. S. Amoli, A. Porgam, Z. B. Sadr, and F. Mohanazadeh, J. Chromatogr., A, 2006, 1118, 82.

6. M. I. Uvarova, G. D. Brykina, and O. A. Shpigun, J. Anal. Chem., 2000, 55, 910.

7. Z. Shi and C. Fu, Talanta, 1997, 44, 593.

8. L. E. Grishina, G. D. Brykina, and O. A. Shpigun, J. Anal. Chem., 1995, 50, 826.

9. S. Oszwaldowski and M. Jarosz, Chem. Anal. [Warsaw], 1997, 42, 739.

10. L. Sommer and J. Dolezal, Scr. Chem., 1997, 26, 65.

11. J. Dolezal and L. Sommer, Scr. Chem., 1995, 24, 73.

12. T. Yasui, A. Yuchi, H. Yamada, and H. Wada, J. Chromatogr., A, 1994, 659, 359.

13. H. Niwa, T. Yasui, T. Ishizuki, A. Yuchi, H. Yamada, and H. Wada, Talanta, 1997, 45, 349.

14. H. Niwa, T. Yasui, A. Yuchi, H. Yamada, and H. Wada, J. Chromatogr., A, 1997, 789, 491.

15. T. Yasui, T. Ohnishi, Y. Mizuno, N. Ohata, and H. Yamada, Bunseki Kagaku, 2003, 52, 1121.

16. H. Niwa, T. Yasui, A. Yuchi, H. Yamada, and H. Wada, Anal. Sci., 1997, 13, 137.

17. H. Niwa, T. Yasui, A. Yuchi, H. Yamada, and H. Wada, Anal. Sci., 1997, 13, 643.

18. T. Yasui, H. Niwa, Y. Niwa, H. Yamada, and H. Wada, ITE Lett. Batt. New Tech. Med., 2001, 2, 225.

19. C. Zhang, J. Miura, and Y. Nagaosa, Anal. Sci., 2005, 21, 1105.

20. P. Jones, M. Foulkes, and B. Paull, J. Chromatogr., A, 1994, 673, 173.

21. P. Jones and P. N. Nesterenko, J. Chromatogr., A, 1997, $789,413$.

22. B. Paull, P. Nesterenko, and P. R. Haddad, Anal. Chim. Acta, 1998, 375, 117.

23. B. Paull and P. R. Haddad, TrAC Trends Anal. Chem., 1999, 18, 107.

24. M. J. Shaw, S. J. Hill, and P. Jones, Anal. Chim. Acta, 1999, 401, 65.

25. M. J. Shaw, P. Jones, and P. N. Nesterenko, J. Chromatogr., A, 2002, 953, 141.

26. A. Kawase, Anal. Chim. Acta, 1972, 58, 311.

27. D. Betteridge and D. John, Analyst, 1973, 98, 377.

28. S. Shibata, "Chelates in Analytical Chemistry", ed. H. A. Flaschka and A. J. Barnard, Jr., 1972, Vol. IV, Marcel Dekker, New York, 1.

29. G. Nakagawa and H. Wada, Nippon Kagaku Zasshi, 1964, $85,202$.

30. G. Nakagawa and H. Wada, Nippon Kagaku Zasshi, 1962, 83, 1098 .

31. M. Liua, K. Ushidaa, A. Kira, and H. Nakahara, Thin Solid Films, 1998, 327 - 329, 491.

32. V. J. Jacques and M. Isabelle, Synth. Commun., 2001, $31(1), 1$.

33. J. Nawrocki, J. Chromatogr., A, 1997, 779, 29.

34. L. G. Sillen and A. E. Martell, "Stability Constants of Metal-ion Complexes, and Supplement No. I", 1964 and 1971, The Chemical Society, London.

35. E. Högfeldt, "Stability Constants of Metal-ion Complexes, Part A", IUPAC, 1982, Pergamon, Oxford. 